\title{
Formação inicial de professores: contradições do Programa Institucional de Bolsas de Iniciação à Docência (PIBID)
}

\author{
Initial teacher training: contradictions of the Scholarship \\ Institutional Program of Initiation to Teaching (SIPIT)
}

Formación inicial de profesores: contradicciones del Programa Institucional de Becas de Iniciación a la Docencia (PIBID)

\author{
MARGARITA ViCTORIA RODRIGUEZ ${ }^{D}$ \\ ANDRÉ MALINA \\ CARoline Correia MacieliDc
}

\section{Resumo}

O presente artigo tem por objetivo explicitar contradições presentes nas políticas de formação inicial de professores, especialmente aquelas que se destacam no interior do Programa Institucional de Bolsas de Iniciação à Docência (PIBID). As relações estabelecidas entre o aluno bolsista e as dinâmicas do programa referem-se ao ponto central de investigação e análise. Para tanto, o procedimento metodológico adotado foi a análise da legislação que regula o programa e a utilização de entrevistas semiestruturadas com dois coordenadores institucionais: um do PIBID/UFMS, e outro do PIBID/UEMS. Evidencia-se que a distorção na atuação do pibidiano quando realiza sua formação prática na escola pública e a dificuldade em garantir a permanência desses acadêmicos de licenciatura em seus cursos são as principais contradições encontradas nos dois eixos de investigação.

Palavras-chave: Formação inicial de professores. PIBID. Política Educacional.

\section{Abstract}

The purpose of this article is to make explicit contradictions in the initial teacher traiing policies, essentially those that stand out within of the Scholarship Institutional Program of Initiation to Teaching (SIPIT). The relations established between the scholarship student and the Program's

\footnotetext{
a Universidade Federal de Mato Grosso do Sul (UFMS), Campo Grande, MS, Brasil. Doutora em Educação, email: poroyan@uol.com.br

b Universidade Federal do Rio de Janeiro (UFRJ), Rio de Janeiro, RJ, Brasil. Doutor em Educação Física, email: andremalina@yahoo.com.br

c Universidade Federal de Mato Grosso do Sul (UFMS), Campo Grande, MS, Brasil. Mestre em Educação, email: carol.maciel85@hotmail.com
} 
dynamics refer to the central point of investigation and analysis. To that and the methodological procedure adopted was the analysis of the legislation that regulates the program and the use of semistructured interviews with two SIPIT's institutional coordinators. The evidences related the distortion in the "pibidianos" performance when it performs its practical formation its practical formation in the public School and the difficulty to ensure the permanence of these undergraduated studants in its courses are the main contradictions found in the two investigation axes.

Keywords: Initial teacher training. SIPIT. Educational Politics

\section{Resumen}

El presente artículo tiene por objetivo explicitar las contradicciones presentes en las políticas de formación inicial de profesores, especialmente aquellas que se materializan en el interior del Programa Institucional de Becas de Iniciación a la Docencia (PIBID). Las relaciones establecidas entre el alumno becario y el programa son el punto central dela investigación y análisis. Para ello, el procedimiento metodológico adoptado fue la análisis de la legislación que regula el programa e la utilización de entrevistas semiestructuradas con dos coordinadores institucionales: uno del PIBID/UFMS, y otro del PIBID/UEMS. Se evidencia que la distorsión en la actuación del pibidiano cuando realiza su formación práctica en la escuela pública y la dificultad en garantizar la permanencia de los estudiantes en sus cursos son las principales contradicciones encontradas en los dos ejes de la investigación.

Palabras clave: Formación inicial de profesores. PIBID. Políticas Educacionales.

\section{Introdução e aspectos metodológicos}

A primeira década dos anos 2000 foi marcada pela implementação de programas de formação inicial e continuada de professores financiados pelo governo federal em parceria com os entes federativos (municípios, estados e o Distrito Federal). Essa tendência teve como finalidade superar fragilidades estabelecidas pelo aligeiramento da formação no ensino superior, as quais ocorreram devido às regulamentações viabilizadas no decorrer dos anos de 1990.

O Programa Institucional de Bolsas de Iniciação à Docência (PIBID) refere-se a um dos programas implementados no decorrer dos anos 2000. É um programa de formação inicial de professores estruturado pelo Ministério da Educação (MEC) e possui organização administrativo-burocrática realizada pela Coordenadoria de Aperfeiçoamento de Pessoal de Nível Superior (CAPES). Seu financiamento está amparado pelo Fundo Nacional de Desenvolvimento da Educação (FNDE). Mediante a Portaria normativa $n^{\circ} 38$, de 12 de dezembro de 2007, foi criado o programa e regulamentado posteriormente pelo Decreto $n^{\circ} 7.219$ em 24 de junho de 2010. O propósito foi incentivar a iniciação à docência e contribuir para o aperfeiçoamento da formação inicial das licenciaturas, além da perspectiva de melhoria da qualidade da educação básica. 
Um levantamento de produções acadêmicas realizado na base de dados da página da CAPES revelou um mapeamento com volume significativo de artigos que apresentavam discussões relevantes sobre o referido programa. Ao utilizar o descritor PIBID foi obtido o resultado de 424 artigos. Pelos títulos e resumos das publicações encontradas, notaram-se, em sua maioria, debates que explicitavam a sua importância no processo de formação inicial em diversas áreas disciplinares.

Essa perspectiva favorável à formação inicial por meio do PIBID pode ser observada nos debates abordados por Souza e Martins Filho (2016), Moryama, Passos e Arruda (2013), Noffs e Rodrigues (2016) e Morais e Ferreira (2014), por exemplo, bem como em outras produções acadêmicas encontradas. Especialmente, mediante os relatos dos acadêmicos bolsistas, os respectivos artigos apresentaram evidências salutares à proposta do programa. Foi verificado, portanto, destaque em diversos aspectos, entre eles: a maior articulação entre a teoria e a prática, o reconhecimento do contexto escolar, o trabalho coletivo e colaborativo, o crescente interesse pela docência, a reflexão sobre as próprias ações em salas de aula, a melhora em sua aprendizagem e prática na alfabetização entre outras considerações edificadoras.

Sem desconsiderar tais indicativos relevantes, o presente artigo apoiado na categoria contradição aponta que "as determinações mútuas das coisas se encontram em relação interna de antagonismo. Cada realidade no seu devir é limitada por outra, e assim a totalidade é sempre aberta a novas determinações” (CURY, 1985, p. 30). Por isso, busca-se explicitar os possíveis limites das políticas de formação inicial, especialmente sob o aspecto da atuação dos acadêmicos bolsistas, considerando as relações dos contrários, que por ora avançaram, e ora recuaram a partir dos elementos próprios do PIBID.

Ressalta-se que este artigo é fruto de uma pesquisa sistemática tendo o PIBID como temática central. Em um dos processos do desenvolvimento da respectiva inquirição foram selecionados os artigos com discussões acerca do programa, e desses Mateus (2014), Carvalho (2013) e Souza (2014) demonstraram aproximação com a concepção de debate por um viés da contradição. Com base nisso, foram identificados alguns limites no campo da regulamentação e desenvolvimento do programa, como os termos utilizados nos editais, os valores das bolsas, as reuniões entre os participantes e as normativas reguladoras.

Além dos autores selecionados, após a leitura sistêmica de teses e dissertações na página da Biblioteca Digital Nacional de Teses e Dissertações (BDTD) a respeito do 
PIBID, a partir dos descritores PIBID e PIBID políticas formação, duas teses destacaram-se por também evidenciar conflitos na execução do programa. A tese de Girotto (2013), subsidiada por entrevistas com os pibidianos, apontou criticamente existir uma tendência das ações do programa ao desprezo à pesquisa como um seguimento dialético entre universidade-escola. Outrossim, o autor ressaltou uma inclinação do programa à fragmentação do conhecimento e a reclusa ação dos professores em comunhão à configuração produtivista-aplicacionista presente em várias dimensões da sociedade.

A tese de Deimling (2014), na mesma linha da contradição de Girotto (2013), considerou que o PIBID mostra-se um elemento importante para a formação dos futuros licenciados. A precariedade da educação básica constituída pelas políticas educacionais brasileiras, as quais repercutem na formação e trabalho do professor, no entanto, afetam negativamente os alunos-bolsistas, fazendo-os refletir sobre a condição de ser professor.

Dessa forma, com a proposta de ampliar as discussões sobre o movimento dialético do programa, o presente artigo tem como objetivo explicitar as contradições presentes nas políticas de formação inicial de professores, especialmente aquelas que amparam a formação do acadêmico de licenciatura por meio do PIBID. Para tal, as relações estabelecidas entre o aluno bolsista e as dinâmicas do programa foram escolhidas como um problema a ser investigado e analisado com o propósito de evidenciar possíveis incongruências presentes no decorrer da implementação do programa em duas universidades públicas do Mato Grosso do Sul. Visando sistematizar tal investigação, dois eixos principais foram definidos:

1. A atuação dos pibidianos participantes nas universidades investigadas de Mato Grosso do Sul;

2. O processo de permanência do acadêmico (pibidiano) no ensino superior.

Os procedimentos de investigação utilizados foram análises da regulamentação do programa e de entrevistas semiestruturadas realizadas com dois coordenadores institucionais do PIBID: um da Universidade Federal de Mato Grosso do Sul (UFMS), que permaneceu no cargo entre 2007 e 2017, e o outro da Universidade Estadual de Mato Grosso do Sul (UEMS) que se manteve na respectiva função de 2011 a 2018.

A escolha dos coordenadores institucionais para perscrutação foi priorizada por considerá-los como sujeitos que estabelecem a função de gestor do PIBID nas instituições e, portanto, poderiam ter uma visão mais ampliada sobre os processos do programa, tanto 
em relação à regulamentação quanto à relevância pedagógica, o interesse e as desistências. Levou-se em conta a possibilidade de a maior experiência desses coordenadores propiciar condições de análises para além das aparências, com maior criticidade, se comparado aos alunos bolsistas.

As questões elaboradas para entrevista foram organizadas em quatro perguntas iniciais, que se ampliaram durante as respostas dos entrevistados e estiveram centradas em três pontos principais: a) a relevância pedagógica do programa; b) a relevância social proporcionada pelo programa; c) e a contribuição do programa para as licenciaturas. Para o presente artigo foram selecionados os relatos vinculados à atuação do pibidiano e à relevância do programa para a formação inicial.

A escolha dos recortes da regulamentação que proporcionaram subsídios para análise foi demarcada especialmente sobre os objetivos do PIBID, as funções de cada participante do programa e os valores das bolsas por função. As informações das entrevistas foram relacionadas com as das normativas na perspectiva de tomarem maior consistência para perscrutação. A categoria contradição, com referência central em Cury (1985), foi utilizada para o processo de análise da regulamentação do programa e os relatos dos coordenadores institucionais entrevistados e sofrerá maior aprofundamento para sua compreensão no primeiro momento do artigo.

Assim, à frente seguem: de forma sintética a fundamentação da categoria contradição (item 1) e o processo de implementação das políticas de formação de professores e do PIBID, bem como sua regulamentação (item 2). Em seguida, as entrevistas analisadas, verificando-se, como discussão central, possíveis contradições na atuação do aluno-bolsista do PIBID (item 3). Após isso, há o debate que aborda o contrassenso, envolvendo a permanência do pibidiano na universidade diante dos pressupostos estabelecidos no setor político (item 4).

\section{A contradição e o movimento dialético na educação}

Assim como apresentado no processo introdutório, os procedimentos metodológicos escolhidos para alcançar o objetivo do presente artigo foram a utilização da regulamentação do programa juntamente de entrevista semiestruturada com dois coordenadores institucionais do PIBID de Mato Grosso do Sul. As informações coletadas foram analisadas com base em teoria específica e sistemática. 
Diante das questões delineadas, cabe acentuar que tais análises estiveram subsidiadas sob a concepção da contradição que compreende a ideia do movimento contraditório da sociedade capitalista, assentado no motor da luta de classes (CURY, 1985). Considera-se que a educação é parte desse movimento e, desse modo, sua realidade só pode ser vista para além das aparências se assimilada nesse processo de antagonismo.

Althusser (2008) explica que na sociedade capitalista predomina uma relação entre movimento estrutural promovido pelo Estado, na compreensão entre repressão e ideologia enquanto aparelhos estatais. Gramsci (2014a, 2014b), em outra perspectiva, aborda que esse mesmo Estado perde força em formas societárias nas quais o movimento contraditório acentua possibilidades de luta por hegemonia, em especial, aquelas com a sociedade civil organizada (GRAMSCI, 2014a, 2014b).

Nessa perspectiva gramsciana, é possível que governos populares acentuem esforços na direção de interesses diversos do que grupos sociais compreendem como mais relevantes, na forma e/ou conteúdo. Daí que organizações sociais, por exemplo, emergiriam, inclusive pressupondo a formação de intelectuais orgânicos no seu interior (MALINA, 2016). A materialização desse processo pode resultar em um movimento contraditório dentro de forças pressupostamente do mesmo espectro ideológico.

Em uma visão diversa, chamada ortodoxa, autores acentuam que as contradições não se desenvolvem na sociedade e entre sociedades, de forma igual. Para Althusser, "ainda temos de aprender o essencial: a lei do desenvolvimento desigual das contradições” (2015, p. 162).

Nesses termos, ainda que de forma sintética, Cury pôde, em relação à categoria contradição, de forma mediada para a educação, realçá-la pela forma com a qual se une à dialética pelo seu sinônimo essencial em qualquer modelo social: o movimento. No movimento da sociedade capitalista, as relações sociais estruturantes entram em fase de potencial colapso caso se considere o movimento interno da relação entre classes sociais. Isso pode ocorrer, pela visão de Marx (2002), na forma de trabalho abstrato, mas também na maneira pela qual as relações sociais de trabalho entram em contradição com as relações sociais de produção. De maneira complexa, as formas contraditórias do sistema capitalista aparecem na própria forma ontológica do homem, ainda que sempre inserido nas relações sociais que abrangem, por conseguinte, relações institucionais. 
Considera-se a educação uma atividade humana participante da totalidade da organização social, que faz parte das aspirações e necessidades humanas objetivas de um determinado momento histórico-social. Nessas condições, as relações de produção do sistema capitalista, bem como suas relações de classes, em unidade dialética, não permitem a exclusão da educação em seu movimento. E é do antagonismo entre as classes dominante (burguesa) e dominada (trabalhadora) que a dominante tenta a direção sobre o conjunto da sociedade por meio do consenso. Para se manter como tal, necessita-se que suas condições sejam reproduzidas, sem que as contradições do próprio sistema a vejam à luz do dia (CURY, 1985).

Destaca-se, ainda, sobre essa relação entre educação e contradição:

[...] dá-se à categoria da contradição um caráter central, especialmente nas relações que podem ser estabelecidas para uma análise do fenômeno educativo. As falhas nos discursos pedagógicos, sejam de caráter homogêneo ou de equívoco, nascem da não captação ou do escamoteamento da contradição. Por isso, não dão conta do real tal como este se apresenta sob a sociedade capitalista (CURY, 1985, p. 16).

Compreende-se que, para analisar as políticas de formação inicial de professores, bem como as relações estabelecidas com o pibidiano, não se pode considerar os seus processos isolados, fora do movimento dialético de luta de classes estabelecido, inclusive, no cerne das próprias instituições educativas. Por isso, é importante estar alerta à discussão de Cury (1985) quando explicita que "a exclusão do movimento contraditório falsifica a conceituação do objeto, já que a contradição que habita o objeto e o define como tal é posta de lado" (p. 22). Ou seja, a realidade concreta do PIBID e suas instâncias de desenvolvimento estão baseadas na não exclusão de seu movimento complexo e multifacetado institucionalizado na sociedade de classes.

É importante elucidar, sob a perspectiva do movimento dialético, que nem mesmo os processos revolucionários sofrem rupturas totais, mesmo sendo uma assertiva questionável em certos vieses de corte marxista. Todo grupo social emergiu na história a partir da estrutura econômica anterior e, como expressão de desenvolvimento, encontrou categorias intelectuais preexistentes, que apareciam como representantes de uma continuidade histórica, e que não foi interrompida nem mesmo pelas mais radicais modificações das formas sociais e políticas existentes na humanidade (COUTINHO, 2011). Por isso os avanços e os limites socialmente organizados e o velho inerentemente como parte no movimento do novo. 
Destaca-se, com isso, que a dinâmica da contradição está vinculada às determinações mútuas das coisas que se encontram em relação interna de antagonismo. Considera-se que a realidade é limitada por outra e a totalidade está sempre aberta a novas determinações contendo elementos anteriores (CURY, 1985).

E é sob esse caráter inacabado, em valorização à unidade do movimento dialético da luta de classes, que as análises das políticas de formação inicial, com ênfase na atuação do pibidiano buscaram estabelecer as múltiplas determinações a que o programa está vinculado. Por isso, a intenção em reconhecer a história das referidas políticas de formação, sua origem e as políticas sociais que se relacionam, para que seja viável enxergar além das aparências preestabelecidas.

\section{Política de formação inicial de professores: vinculação com a educação básica}

O PIBID foi constituído no processo de implementação das políticas de formação docente desenvolvidas na primeira década dos anos 2000. Suas influências político-ideológicas estiveram fundamentadas no projeto neoliberal, cuja perspectiva dominou o panorama político brasileiro desde 1990. No decorrer dos anos 2000, no entanto, assumiu-se uma maneira singular de governança que permitiu maior financiamento para as políticas educacionais.

Apesar de o PIBID estar situado em um processo de fomento das políticas de formação docente dos anos 2000, salienta-se que a necessidade da sua criação baseia-se em precedentes históricos organizados socialmente no âmbito da educação. Rodríguez e Vargas (2008) verificaram que as políticas de formação de professores vinham sendo debatidas em fóruns internacionais desde meados da década de 1960. Nesse processo de diversos encontros, em maio de 1996, a exemplo, foi realizada na Jamaica a VI Reunião de Ministros de Educação da América Latina e o Caribe, de significativa relevância para as políticas de formação de professores, haja vista que foi contemplada com a elaboração do documento Educación, Democracía, Pazy Desarrolo. (OREAL/UNESCO, 1996).

Sobre a influência do movimento internacional no cenário brasileiro, Freitas (2002) e Rodrigues e Kuenzer (2007) elucidaram que as políticas de formação de professores, implementadas no Brasil a partir de 1990, apresentaram uma perspectiva de caráter neoliberal marcada pelo desenvolvimento de habilidades e competências exigidas pela 
produção toyotista e suas consequências mercadológicas. Tal perspectiva é corroborada, entre outros indicadores, pelas orientações do documento internacional, produzido pelo Banco Mundial (BM) (1994), La Enseñanza Superior — las lecciones derivadas de la experiência, as quais nortearam a desvalorização das instituições universitárias e de pesquisa e o incentivo à expansão de instituições privadas e adequação da educação superior à demanda do mercado.

Essas orientações estabelecidas no documento do BM propiciaram a criação de normativas que regulamentaram as políticas de formação inicial e, consequentemente, configuraram um processo de aligeiramento dos cursos nas Instituições de Ensino Superior (IES), assim como discute Freitas (2002), fato que gerou fragilidade e superficialidade na formação inicial por essa via.

Sob influência dos mecanismos internacionais, o sistema educacional brasileiro, por meio da regulamentação da Lei de Diretrizes e Bases da Educação Nacional (LDBEN) e a Resolução CP no 04/1997, aprovou as orientações gerais para a construção de novas diretrizes curriculares para os cursos de graduação definindo as reformulações na formação inicial. Posteriormente, tal resolução e o Parecer no 115/1999, junto à criação dos institutos superiores, determinaram os Referenciais Curriculares para Formação de Professores (1999). Esse processo evidenciou um procedimento de flexibilização curricular adequado às demandas produtivas (FREITAS, 2002).

Em 2002, com a vitória para a presidência de Luiz Inácio Lula da Silva, um líder sindical, do Partido dos Trabalhadores (PT), houve a esperança de uma resistência ao Fundo Monetário Internacional (FMI), à contenção do fluxo de capitais para o sistema financeiro internacional, ao combate do projeto da Área de Livre Comércio da Américas (ALCA), entre outras questões que geraram infortúnio à classe trabalhadora. Após um ano e meio no poder, contudo, identificou-se a subordinação aos setores financeiros e à neoliberalização como estratégia de governo (ANTUNES, 2006).

Ressalte-se, entretanto, que o movimento estabelecido nos governos liderados pelo Presidente Lula (2003-2010) não se refere a um processo linear. Compreende-se aqui que a história nesse período foi marcada por fatos complexos e contraditórios, em especial no campo das políticas educacionais. Especificamente sobre as políticas de formação inicial, apesar da aproximação do governo Lula (2003-2010) com os setores financeiros, novas medidas foram tomadas na tentativa de superar críticas referentes ao formato aligeirado da 
formação inicial desenvolvida no governo anterior. Cabe destacar, portanto, algumas singularidades como forma de compreender que o processo de fragilidade estabelecido nos anos de 1990 não se apresenta da mesma maneira e com as mesmas condições históricas e materiais dos anos 2000.

$\mathrm{Na}$ perspectiva de sobrepujar tais condições de fragilidade no processo aligeirado da formação inicial, foi proposta na primeira década dos anos 2000 a criação de programas de formação continuada e o incentivo para implementação de programas de formação inicial, como o Pró-Licenciatura, por exemplo, iniciado no ano de 2005. Os programas implementados, entretanto, não foram suficientes para superar a debilidade da formação pretendida mediante a regulamentação orientada pelos organismos internacionais (GATTI, 2012).

A situação viabilizada de avanços e recuos observada nas relações da regulamentação e materialização das políticas de formação inicial estabelecidas na primeira década dos anos 2000, especialmente no período do governo Lula (2003-2010), pode ser explicada, baseada na concepção do movimento dialético em Cury (1985), o qual reforça a luta dos contrários na busca da superação da própria contradição, que ao se superar é reconquistada em um nível superior.

Entende-se que, mediante a regulamentação dos programas, buscou-se tentar superar a contradição que se desenvolveu acerca do aligeiramento da formação inicial sob orientação dos setores financeiros. Em contrapartida, à medida que os programas foram se materializando, novos limites, em outros níveis, foram sendo apresentados.

De fato, os programas mostram, nos objetivos para sua implementação, a tentativa da melhoria na formação inicial dos professores e a busca pela qualidade da educação básica — tanto que no anexo III da Resolução no 34 os objetivos do Pró-Licenciatura pretendem:

[...] a melhoria da qualidade de ensino na escola em que atuam e a ampliação das possibilidades de aprendizado por seus alunos [...] assegurar que o investimento feito na formação do docente resulte em melhoria real na qualidade do ensino oferecido nas escolas das redes públicas. Assim, serão enviados esforços buscando estimular os demais profissionais da escola em que atua o professoraluno desse Programa a participarem de programas de formação inicial ou continuada (BRASIL, 2005, p. 10-11).

Entretanto, na prática, houve ainda insatisfações do ponto de vista para atingir os objetivos previstos de superar as fragilidades no campo da formação docente e da educação básica. Essa situação pode ser amparada teoricamente no que Cury (1985) reforça sobre as falhas dos discursos pedagógicos, os quais nascem, segundo ele, da captação ou do 
escamoteamento da contradição, e que não dão conta do real como se apresenta na sociedade capitalista.

Diante de tais dificuldades, o governo brasileiro, na segunda metade da primeira década dos anos 2000, com perspectiva de atingir objetivos e metas na formação inicial, encaminhou via Ministério da Educação uma nova estrutura para a CAPES, a partir do Projeto de Lei (PL) no 7.569-D/2006, cuja proposta apresentava como objetivo "[...] institucionalizar programas de formação inicial e continuada, bem como o desenvolvimento de metodologias educacionais inovadoras, visando à qualificação de recursos humanos para a educação básica" (BRASIL, 2006). Assim, mediante a Lei no 11.502/2007, art. 2 , \ 2, a CAPES passou a ter como finalidade:

Induzir e fomentar, inclusive em regime de colaboração entre os Estados, os municípios e o Distrito Federal e exclusivamente mediante convênios com instituições de ensino superior públicas ou privadas, a formação inicial e continuada de profissionais do magistério (BRASIL, 2007, não p).

Percebeu-se, após esse processo regulatório da CAPES, maior intervenção do Estado no campo da formação inicial. O PIBID foi criado a partir desse movimento voltado exclusivamente para as licenciaturas — em 12 de dezembro de 2007, por meio da Portaria Normativa $n^{\circ}$ 38, com fins de fomentar a iniciação à docência de estudantes das instituições federais de educação superior e preparar a formação de docentes em nível superior, em curso presencial de licenciatura de graduação plena para atuar na educação básica pública.

Dada a complexidade e as contradições do movimento conjuntural que envolve as políticas educacionais, inclusive relativas ao PIBID, considera-se que outros aspectos no interior do programa puderam apresentar incongruências relacionadas ao sistema educacional e à formação docente, fato passível de investigação. Nesse caso, cabe compreender, inicialmente, a organização interna do PIBID, que se constitui de forma peculiar.

O programa possui funções específicas, que definem o valor das bolsas ${ }^{1}$. Os participantes do programa são acadêmicos de licenciaturas, professores da escola pública

\footnotetext{
${ }^{1}$ Bolsa de Iniciação à Docência - para estudantes de licenciatura das áreas abrangidas pelo subprojeto. Valor: $\mathrm{R} \$ 400,00$ (quatrocentos reais). Bolsa de Supervisão - para professores de escola pública de educação básica que supervisionam, no mínimo, cinco e, no máximo, dez bolsistas da licenciatura. Valor: R\$ 765,00 (setecentos e sessenta e cinco reais). Bolsa de Coordenação de Área - para professores da licenciatura que coordenam subprojetos. Valor: 1.400,00 (um mil e quatrocentos reais). Bolsa de Coordenação Institucional - para o professor da licenciatura que coordena o projeto Pibid na IES.
} 
da educação básica (denominado supervisor) e professores das IES, sob as funções de coordenador de área (responsáveis pelos subprojetos nas licenciaturas), coordenador de gestão (responsáveis pelos processos educacionais) e coordenador institucional das IES (organizam e administram a abertura de subprojetos) (BRASIL, 2018).

Conforme orientam as principais atribuições do PIBID, em seu veículo eletrônico oficial (CAPES/PIBID), o estudante de licenciatura é figura central do programa, que foi desenhado para enriquecer sua formação prática (BRASIL, 2014). Não obstante, seus objetivos, atualizados pelo edital $\mathrm{n}^{\circ} 7 / 2018$, complementam-se em contribuir com a articulação entre teoria e prática necessárias para a formação docente; criar oportunidades de criação e participação em experiências metodológicas, tecnológicas e práticas docentes de caráter inovador e interdisciplinar na realidade da escola pública; promover a integração entre educação superior e educação básica; mobilizar os professores da educação básica como coformadores dos futuros docentes e contribuir para a valorização do magistério.

Sem ignorar a importância das outras funções e a condição de interdependência entre os integrantes, busca-se, a seguir, explicitar as contradições presentes na relação estabelecida acerca do aluno bolsista no processo de desenvolvimento do programa.

\section{Atuação do aluno bolsista (ou pibidiano) no processo de formação inicial do PIBID}

Especificamente nesse item, pretendeu-se realizar a discussão referente ao primeiro eixo de investigação, que se refere à atuação dos pibidianos participantes das universidades perscrutadas de Mato Grosso do Sul.

Nesse sentido, o coordenador institucional da UEMS (2016), indagado a respeito da relevância pedagógica do PIBID, apresentou sua perspectiva a respeito do engajamento do aluno bolsista na formação inicial, em especial os pibidianos/UEMS, e fez refletir sobre conflitos que podem ocorrer na atuação desse acadêmico, e como ele se diferencia quando entra em contato com o espaço escolar:

Então, nos relatos que a gente ouve dos nossos coordenadores, e até de professores que não são
coordenadores PIBID, professores da licenciatura, é que nos debates das disciplinas o bolsista
PIBID se diferencia, por quê? Porque ele já tem uma bagagem pra discutir a teoria. [...] desde o início
do curso o aluno já consegue fazer um debate sobre teoria e prática mais qualificado, porque ele já
está vivenciando isso na escola [...] o pibidiano, de certa forma, é um apoio para o professor lá, vai

Permitida a concessão de uma bolsa por projeto institucional. Valor: R $1.500,00$ (um mil e quinhentos reais) (BRASIL, 2018) 
ter muitos projetos, são inovadores, que o professor não teria tempo na sua correria do seu dia a dia de planejar, de executar, então ele discute com o coordenador de área e com os alunos seu planejamento, e implementam vários projetos, que sozinho ele não teria condições de implementar (UEMS, 2016).

Fica evidenciado, inicialmente, o potencial transformador do PIBID, mediante a atuação do pibidiano, marcado por um delineamento que corresponde a um dos objetivos do programa em relação ao aluno bolsista: contribuir para a articulação entre a teoria e a prática na formação do futuro docente. Segundo o entrevistado, na medida em que os pibidianos são comparados aos outros alunos dos cursos de licenciatura, destacam-se por conseguirem estabelecer discussões que associam teoria e prática. Inclusive, Souza e Martins Filho (2016) corroboram teoricamente com esse discurso do coordenador institucional em sua pesquisa, pois ressaltam a maior articulação entre teoria e prática do acadêmico participante do PIBID.

No entanto, as múltiplas determinações vinculadas à dinâmica do programa dão um tom contraditório no relato do coordenador institucional da UEMS na medida em que o aluno bolsista na escola parece tornar-se um auxiliar do supervisor. Essa circunstância aparenta estar compensando precariedades da escola pública associadas ao trabalho docente, em detrimento da formação inicial do aluno bolsista fundamentada nos objetivos estabelecidos pelas normas do programa.

Coutinho (2011) auxilia a compreensão dessa situação contraditória, complexa e não linear. Segundo o autor, as rupturas não ocorrem nem mesmo nas alterações mais radicais das formas sociais e políticas. Cury (1985) ainda salienta as limitações do contexto, que está sempre sob o antagonismo de outro, aberto a outras determinações que contêm configurações anteriores.

Nesse sentido, considera-se que o PIBID pode ser um programa relevante para a formação inicial, especialmente para o aluno bolsista que em processos anteriores vivenciou um tipo de formação mais fragmentada e distante de sua atividade prática. Entretanto, a formação inicial é parte da educação, que está inserida em um sistema de interesses relacionado à luta de classes. Nesse processo, a escola pública, que se refere ao principal ambiente de formação do pibidiano, possui um pequeno investimento financeiro oriundo de um Estado burguês e, desse modo, relaciona-se a um dos determinantes da qualidade da formação inicial dos licenciandos. 
Tal contradição na atuação do pibidiano viabilizada pela falta de valorização da educação básica pública pode ser percebida também a partir do relato do coordenador institucional da UFMS (2016), quando indagado sobre 1) O interesse dos cursos em participar do programa; e 2) Se o entrevistado constata desistências. Nesse caso, indaga-se também quais os motivos dessas desistências. A resposta do coordenador institucional da UFMS segue em conformidade à perspectiva do coordenador institucional da UEMS. Ele afirma: "Então, existe uma demanda, tanto dos cursos da instituição como também das escolas. Tipo aquele programa do Sílvio Santos: 'Quem quer PIBID?' Aí aparecem ‘trocentos' diretores aqui na porta, então o interesse é muito grande”. Este fato sinaliza que é um conforto para as escolas, terem os pibidianos em seu interior.

Desse modo, pode-se considerar, mediante indícios discursivos referentes aos relatos dos coordenadores institucionais, que o aluno bolsista ameniza, em certa medida, e talvez de forma imediata, a precarização estabelecida na escola e pode assim proporcionar uma suposta qualidade negada constantemente pelas políticas de governo e de Estado. Dessa forma, a atuação do pibidiano pode ser encarada, ou distorcida, como força de trabalho barata, pois passa a servir de auxílio ao professor supervisor, fato que deveria ser resolvido com investimento e políticas públicas voltadas para a qualidade do trabalho docente, e não com o aproveitamento da presença do acadêmico na escola.

De fato, a educação básica é o nível de ensino que subsidia a formação prática do pibidiano, e não há como negar que se trata de um fragmento do sistema de ensino significativamente prejudicado pelas prioridades orçamentárias dos governos. Deimling (2014), em sua tese defendida sobre o PIBID, salienta a importância do programa para a formação dos licenciandos, mas aponta limites vivenciados pela educação brasileira que repercutem negativamente sobre os alunos-bolsistas, fazendo-os refletir sobre a condição de ser ou não professor. Além disso, a autora considera antagônica a implementação de políticas de formação docente que incentivem os acadêmicos a encarar e superar os ambientes precários construídos pelas políticas educacionais brasileiras.

Oliveira (2006) e Piovezam e Dal Ri (2016) também ajudam a assimilar tal cenário, e discutem com base nas políticas educacionais a precarização do trabalho docente após os anos de 1990. Salientam que a edificação da flexibilização na contratação de professores, o arrocho salarial, a intensificação do trabalho no magistério, a ampliação da jornada de 
trabalho e o relevante aumento de responsabilidades designadas aos professores são questões que afetam significantemente o trabalho docente.

Essas evidências destacadas pelas autoras auxiliam na interpretação dos relatos dos coordenadores institucionais quando apontam a possibilidade de o pibidiano ser um agente de compensação na escola, mesmo quando aparenta estar atuando de forma satisfatória em sua formação inicial. Essa situação reforça a seguinte concepção de contradição, baseada em Cury (1985): no interior da implementação e materialização do PIBID, as múltiplas determinações do programa favorecem a formação inicial dos futuros docentes trabalhadores, na tentativa de superar fragilidades postas socialmente; todavia, ao passo que as dinâmicas do programa se materializam, surgem novos problemas externos, que o influenciam e afetam o seu desenvolvimento.

Os relatos dos dois coordenadores valorizam a peculiaridade do programa em proporcionar que o pibidiano realize sua formação com maior proximidade à realidade da escola pública. Os entrevistados ressaltam que essa prática produz efeitos positivos para a formação do futuro docente. O Coordenador Institucional da UFMS (2016) enfatiza que:

[...] 0 segundo movimento importante também, em decorrência da própria estrutura do PIBID é o fato de que [...] a escola real passou a ser palco dos cursos de formação de professores. Pode parecer uma contradição mas nos cursos de formação de professores em geral tem um estranhamento aos pobres. A escola real, a escola onde as coisas acontecem é uma escola que está muito distante dos cursos de formação de professores. Se fala sobre a escola, mas em momento algum se traz a escola pra dentro dos cursos, e dos agentes da escola no qual eles trabalham. O PIBID rompe com isso, quando o PIBID tem como foco ação na escola. Quando o PIBID transforma a escola em um espaço de formação, ele faz um salto qualitativo em relação ao estágio, por exemplo. [...] essa aproximação com a escola, o diálogo com as pessoas da escola, ela é central. Ela é central porque permite ao aluno participante do PIBID ter contato com aspectos do conhecimento ou uma base de conhecimento que formam o professor e frustram demais os alunos que não são do PIBID.

E o Coordenador Institucional da UEMS (2016), nessa mesma perspectiva, destaca:

Então, a relevância consiste no fato desses alunos poderem participar do ambiente da escola, primeiro desde o início da sua formação. Tem bolsistas, por exemplo, que entraram na universidade em março, e em abril já estavam no PIBID. Então desde o início do curso, os alunos já vão para o ambiente da escola, que é o ambiente de trabalho deles. Então, essa vivência no ambiente da escola é riquíssima, que nós professores de estágio não conseguimos passar pra eles. Então, é o que a gente chama de cultura escolar, as relações entre professor-aluno, entre aluno-aluno, a relação com os outros profissionais da escola, os tempos da escola, os projetos, então tudo isso o bolsista PIBID tem tido experiências durante a sua formação.

Cabe pontuar, portanto, considerando os relatos dos coordenadores $e$ as contradições apresentadas anteriormente, que as relações sociais e institucionais não se desenvolvem de forma linear, exata, nem tampouco com suas problematizações aparentes, 
haja vista o processo de luta de classes estabelecido no movimento da organização estrutural em que o programa está situado.

Nesse caso, é importante perceber o PIBID com elementos que indicam uma configuração na atuação do acadêmico que pode favorecer a sua formação enquanto futuro docente. A alteração de papéis do pibidiano na escola e a acomodação com a precarização da educação pública, entretanto, aparenta ser uma adversidade velada pouco percebida, inclusive, pelos próprios coordenadores institucionais, e que repercute diretamente no desenvolvimento do programa e na formação inicial dos acadêmicos de licenciatura. No entanto, evidencia-se uma problemática que não se encerra nela mesma, e que precisa sofrer questionamentos e uma ampliação de debates nesse campo.

\section{A permanência do aluno e incentivo financeiro para a formação inicial docente}

O processo de permanência no ensino superior proporcionado pelo PIBID estende-se ao outro eixo de investigação, cuja intenção é apresentar outras possíveis contradições provenientes de uma organização que pode não se encerrar no próprio programa.

Para abranger, mesmo que brevemente, as questões político-sociais que envolvem a origem do programa, destaca-se, preliminarmente, que o PIBID foi implementado em um contexto marcado por um plano de governo. O referido plano, denominado Plano Plurianual (PPA) de 2004-2007, estabeleceu algumas metas sociais para o país, e o programa em sua materialização apresentou consonância com as metas previstas. Segue abaixo o mega objetivo I (inclusão social e redução das desigualdades sociais), que tem como uma de suas propostas:

Integração entre a política social e a política econômica, derivada do modelo de desenvolvimento adotado. Este realiza a integração entre, por um lado, a inclusão social e a redistribuição da renda e, por outro, os investimentos e o crescimento da renda e do emprego. A universalização dos direitos sociais básicos e a transmissão dos ganhos de produtividade aos salários estabelecem a sinergia entre as políticas sociais e de investimento, promovendo o crescimento por meio da expansão do mercado de consumo popular (BRASIL, 2004).

No campo da educação superior, a partir de 2004, houve uma significativa quantidade de programas que ofertaram bolsas de estudo e assistência estudantil, 
especificamente nesse nível de ensino, com o objetivo de proporcionar acesso e permanência, e ainda indicou, em certa medida, a expansão do mercado de consumo popular e a tentativa da universalização dos direitos sociais básicos. O Programa Institucional de Bolsas de Iniciação Científica (PIBIC), o Programa de Educação Tutorial (PET) (2005), o PIBID (2007) e o Programa Nacional de Assistência Estudantil — PNAES (2010) são alguns dos programas que auxiliaram na permanência do acadêmico no ensino superior (BRASIL, S/D).

Com base na situação representada pelo tempo histórico que marcou os anos de 2007 a 2016, indagou-se, no decorrer da pesquisa, a respeito da relevância social do programa para os bolsistas participantes do PIBID. Os coordenadores institucionais foram questionados acerca dos valores das bolsas e a relevância social do PIBID em relação à condição de permanência no ensino superior possibilitada pelo programa. O coordenador institucional da UEMS relatou que:

[...]a bolsa que o valor deveria ser mudado é a de iniciação à docência, porque realmente, assim, R \$400,00 há cinco anos atrás, que era em 2011, esse valor em 2011 pra hoje, a defasagem já é muito grande [...] Então hoje o valor ideal seria uns R $\$ 600,00$ ou R $\$ 650,00$ [...] vamos pegar 2014, o valor da bolsa estava considerável [...] tinha desistências pontuais: o trabalhador que não se adequou ao horário, o aluno que já estava mal no curso e desistiu [...]. De 2015 pra cá, há um aumento de desistências, que isso pode ser por conta do valor da bolsa também. [...] de repente o aluno vai ganhar um salário mínimo para trabalhar quarenta horas, então quando ele consegue fazer essa relação de que, talvez compense ficar com $\mathrm{R} \$ 400,00$, porque o tempo de dedicação é menor no trabalho, então eu posso me dedicar mais ao estudo, quando ele pode fazer essa análise, então, ele permanece no PIBID. Mas, quando é um aluno carente que necessita pagar o aluguel, pagar a alimentação, e a bolsa não é suficiente, então esse aluno opta por desistir (UEMS, 2016).

E o coordenador institucional da UFMS reforça:

\begin{abstract}
Ah, as bolsas, com certeza são defasadas [...] PIBID, PIBIC e Bolsa Permanência estão congelados. Isso com certeza é um problema para a permanência dos estudantes no projeto [...]. É o que eu digo, em casos pontuais, a pessoa precisa ter uma renda maior, tem compromisso com os familiares. No PIBID, a CAPES não proíbe explicitamente que nós peguemos alunos que trabalham. Então o aluno pode trabalhar e ter uma bolsa PIBID. [...] Não se esqueça que a bolsa de PIBID é de 400 pilas desde 2009. [...] São alunos de cursos noturnos muitas vezes. Então esse é um fator de desistência muito grande. Há claro, aluno que abandona o PIBID, porque chega à conclusão que não quer ser professor. Mas esses são raros (UFMS, 2016).
\end{abstract}

Verifica-se, pelos relatos, que o valor da bolsa de iniciação à docência e a garantia da permanência no ensino superior são limites que perpassam aspectos funcionais do programa. Pode-se considerar que o PIBID venha favorecer a permanência de alguns grupos de sujeitos, que possivelmente dispõem de ajuda financeira externa ou de terceiros. No entanto, os grupos mais desprovidos provavelmente não conseguem se manter com o 
valor da bolsa estabelecido e facilmente trocam os estudos no ensino superior por um emprego que aumente sua renda.

Vale salientar, a partir de uma análise para além das aparências, que existe um movimento de contrários que permeia os valores das bolsas, que se refere às relações de classe estabelecidas socialmente. Essas relações de classe podem não permitir que a bolsa auxilie a permanência no ensino superior de grupos específicos de sujeitos. As análises de Marx (2002) ajudam a elucidar esse cenário quando discutem que as formas contraditórias do sistema capitalista aparecem também na própria forma ontológica do homem, ainda que sempre inserido nas relações sociais que abrangem, por conseguinte, relações institucionais.

Possivelmente, tanto pelos relatos dos coordenadores institucionais quanto mediante outras pesquisas, a precarização da condição social da classe trabalhadora juntamente ao baixo valor das bolsas, e sem reajustes, tornou-se uma problemática que merece ser evidenciada e que pode afetar o desenvolvimento da formação inicial. Tanto que Souza (2014), mediante a observação de depoimentos realizados nas reuniões de balanço das atividades do PIBID, verificou declarações indicativas de insatisfação em relação ao baixo valor da bolsa de iniciação à docência. Segundo o autor, as ocupações laborais, além do projeto e dos estudos que os alunos acabam realizando, as dificuldades de organização no que se referem aos encontros dos coordenadores e os recursos das escolas, que conflitam as ações propostas, são circunstâncias geradoras de "desânimo" nos responsáveis pelos subprojetos.

Aparentemente, trata-se de uma contradição, pois da mesma maneira que o plano de governo juntamente com a proposta de bolsa do PIBID contribuem e auxiliam certas problemáticas sociais estabelecidas, a sua concretização não indica, pelos relatos dos coordenadores institucionais, atingir alguns grupos de sujeitos materialmente desfavorecidos. Desse modo, tanto o Megaobjetivo I do PPA (2004-2007) quanto a permanência dos acadêmicos no ensino superior ainda apresentam fragilidades tendo em vista as múltiplas determinações que dificultam seu alcance em sua forma mais ampla.

Sobre a referida contradição, Cury (1985) destaca que:

A contradição é destruidora, mas também criadora, já que se obriga à superação, pois a contradição é intolerável. Os contrários em luta e movimento buscam a superação da contradição, superandose a si próprios. Na superação, a solução da contradição aparece enriquecida e reconquistada em nova unidade de nível superior. Cada coisa é uma totalidade de movimentos e de momentos e elementos provenientes de suas relações, de sua gênese e de sua abertura (CURY, 1985, p. 30). 
Isso posto, observa-se que a possibilidade da permanência no ensino superior por meio de bolsas, como ocorre no PIBID e outros programas implementados a partir de 2004, pode relacionar-se com a superação de insatisfações anteriores socialmente instituídas. No entanto, o movimento dialético, o qual permite um cenário precarizante da classe trabalhadora, juntamente ao baixo valor da bolsa de iniciação à docência e o seu não reajuste revelou um novo elemento contraditório. Com isso, tais circunstâncias evidenciaram afetar diretamente a formação inicial do pibidiano, pois prejudicam a sua permanência no ensino superior, em especial para aqueles desprovidos de recursos complementares e de baixa renda.

\section{Considerações finais}

A história de incentivo das políticas de formação inicial no Brasil a partir da década de 1990 apresenta uma configuração influenciada pelas políticas neoliberais e por orientações dos organismos financeiros internacionais. Tal cenário implicou a regulamentação das políticas de formação inicial via IES marcada por um aspecto de aligeiramento e superficialidade na formação das licenciaturas.

Como compensação da referida fragilidade no processo de formação docente pelo ensino superior no Brasil, o início dos anos 2000 foi circunscrito por algumas reformas e um arranjo de implementação de programas de formação continuada e inicial, na perspectiva de adequar os docentes às competências exigidas pelas demandas produtivas e mercadológicas. Foi de maneira contraditória, portanto (com o propósito de melhorar a qualidade da formação inicial impossibilitada no seguimento de graduação pelo ensino superior), que o PIBID foi originado no referido contexto.

Tendo como pressuposto a contradição inerente ao processo conjuntural e estrutural em que o programa foi implementado, que se buscou explicitar incongruências no interior do PIBID, especificamente em relação à atuação do aluno bolsista e à possibilidade estabelecida pelo programa de proporcionar a permanência dos acadêmicos no ensino superior mediante a bolsa de iniciação à docência.

Em relação à atuação do aluno bolsista, notou-se que as condições precárias instaladas na educação básica pública, conduzidas pelas prioridades convencionadas pela intensificação e precarização do trabalho docente, desvelaram-se como um contrassenso, no qual o acadêmico pode passar a exercer uma função de auxiliar do supervisor e 
colaborador da escola, em detrimento de uma formação prescrita nos objetivos do programa. Há relevância da sistematização do programa como articulador entre educação básica e educação superior, mas percebe-se a existência da valorização pela distorção ocorrida na atuação do pibidiano. O próprio coordenador institucional caracteriza positivamente que o aluno possa servir como subsídio do supervisor.

Sobre o processo de permanência proporcionado pelo programa, a priori, referiu-se a uma medida para suprir insatisfações socialmente organizadas no campo educacional e social. De fato, em certa medida, a bolsa de iniciação à docência contribui com a permanência do licenciando no ensino superior. No entanto, pôde-se considerar, pelos relatos dos coordenadores institucionais e com base na análise da categoria contradição, que o movimento dialético, que condiciona a precarização da classe trabalhadora, juntamente ao não reajuste das bolsas, em especial de iniciação à docência do PIBID a partir de 2015, caracterizou maior desistência de grupos específicos de acadêmicos: os que possuíam rendas mais baixas, ou os que necessitavam de uma renda substancial para sustentar ou colaborar de maneira significativa no ambiente familiar.

\section{Referências}

ALTHUSSER, L. Por Marx. Campinas, SP: Editora da UNICAMP, 2015.

ALTHUSSER, L. Sobre a Reproducão. Petrópolis, RJ: Editora Vozes, 2008.

ANTUNES, R. L. C. Uma esquerda fora do lugar: o governo Lula e os descaminhos do PT. Campinas: Armazém do Ipê (Autores Associados), 2006.

BANCO MUNDIAL. La Ensenanza Superior. las lecciones derivadas de la experiencia (El Desarrollo en la práctica). Washington: Banco Mundial, 1994. Disponível em: <http://www.worldbank.org> Acesso em: 15 jun. 2018

BRASIL. Ministério da Educação. Coordenação de Aperfeiçoamento de Pessoal de Nível Superior (CAPES). Modalidade de bolsas - PIBID. Brasília, DF, 2018. Disponível em: <http://www.capes.gov.br/educacao-basica/capespibid/pibid> Acesso em: 20 jul. 2018.

BRASIL. Coordenação de Aperfeiçoamento de Pessoal de Nível Superior (CAPES). Principais Atribuições dos Estudantes de Licenciatura - PIBID. Brasília, DF, 2014. Disponível em: <http://www.capes.gov.br/educacao-basica/capespibid/estudantes-de-licenciatura > Acesso em: 20 jun. 2017.

BRASIL. Ministério da Educação. Ações e Programas. Brasília, DF, [20-?]. Disponível em: $<$ http://portal.mec.gov.br/acoes-e-programas> Acesso em: 10 out. 2017.

BRASIL. Ministério da Educação. Resolução CD/FNDE no 34, de 09 de agosto de 2005. Estabelece os critérios de seleção, apresentação e execução dos projetos do programa Pró-Licenciatura. Brasília, DF, 2005. Disponível em: <https://www.fnde.gov.br/acesso-a-informacao/institucional/legislacao/item/4185resolu\%C3\%A7\%C3\%A3o-cd-fnde-n\%C2\%BA-34,-de-9-de-agosto-de-2005> Acesso em: 15 maio 2018. 
BRASIL. Lei $\mathrm{n}^{\circ}$ 11.502, de 11 de julho de 2007. Modifica as competências e a estrutura organizacional da fundação Coordenação de Aperfeiçoamento de Pessoal de Nível Superior - CAPES, Brasília, DF, 2007. Disponível em: <http://www.planalto.gov.br/ccivil_03/_Ato2007-2010/2007/Lei/L11502.htm> Acesso em: 11 jan. 2017.

BRASIL. Lei no 10.933, de 11 de agosto de 2004. Plano Plurianual para o período de 2004/2007, Brasília, DF, 2004. Disponível em: <http://www.planalto.gov.br/ccivil_03/_ato20042006/2004/lei/110.933.htm> Acesso em: 11 jan. 2017.

BRASIL. Projeto de Lei $n^{\circ}$ 7.569-D de 2006. Pretende modificar as competências e a estrutura organizacional da fundação Coordenação de Aperfeiçoamento de Pessoal de Nível Superior - CAPES, Brasília, DF, 2006. Disponível em: $<$ https://www.capes.gov.br/images/stories/download/legislacao/ProjetoLei_756906.pdf > Acesso em: 20 jun. 2018.

CARVALHO, M. R. B. O programa de bolsa de iniciação à docência - PIBID: contribuições e limites no âmbito dos cursos de formação inicial. Revista Metáfora Educacional, Feira de Santana, n. 15, p. 287-302, dez. 2013.

COUTINHO, C. N. O leitor de Gramsci: escritos escolhidos 1916-1935. Rio de Janeiro: Civilização Brasileira, 2011.

CURY, C. R. J. Educação e Contradição elementos metodológicos para uma teoria crítica do fenômeno educativo. São Paulo: Cortez Editora, 1985.

DEIMLING, N. N. M. Programa Institucional de Bolsa de Iniciação à Docência: Contribuições, Limites e Desafios para a Formação Docente. 2014. 307 f. Tese (Doutorado em Educação) — Universidade Federal de São Carlos, São Carlos, 2014.

FREITAS, H. C. L. Formação de professores no Brasil: 10 anos de embate entre projetos de formação. Educ. Soc., Campinas, v. 23, n. 80, p. 136-167, set. 2002. Disponível em: <http://www.scielo.br/pdf/es/v23n80/12928.pdf> Acesso em: 22 maio 2016.

GATTI, B. A. Políticas e práticas de formação de professores: perspectivas no Brasil. In: ENDIPE: ENCONTRO NACIONAL DE DIDÁTICA E PRÁTICAS DE ENSINO, 16., 2012, Campinas. Anais... Campinas: UNICAMP, 2012.2 Disponível em: $<$ http://www.infoteca.inf.br/endipe/smarty/templates/arquivos_template/upload_arquivos/acervo/doc s/0040m.pdf. > Acesso em: 15 maio 2016.

GIROTTO, E. D. Entre a escola e a universidade: o produtivismo-aplicacionismo na formação de professores em Geografia. 2013. 246 f. Tese (Doutorado em Geografia) — Universidade de São Paulo, São Paulo, 2013.

GRAMSCI, A. Quaderni del Carcere, Volume Secondo: Quaderni 12-29 (1930-1933). Torino: Editora Giulio Einaudi, 2014a.

GRAMSCI, A. Quademi del Carcere, Volume Terzo: Quaderni 6-11 (1932-1935). Torino: Editora Giulio Einaudi, 2014b.

MALINA, A. Gramsci e a Questão dos Intelectuais. Campo Grande, MS: Editora da UFMS, 2016.

MARX, K. O Capital: crítica da economia política: livro I. São Paulo, SP: Editora Civilização Brasileira, 2002.

MATEUS, E. F. Um esboço crítico sobre "parceria" na formação de professores. Educação em Revista, Belo Horizonte, v. 30, n. 3, p. 355-384, jul./set. 2014. Disponível em: <http://www.scielo.br/pdf/edur/v30n3/v30n3a16.pdf>. Acesso em: 21 jul. 2018. 
MORAIS, J. K. C.; FERREIRA, M. A. S. Profissionalização Docente: construindo saberes a partir da prática do PIBID. Holos, v. 5, p. 112-120, nov. 2014. Disponível em: <http://www2.ifrn.edu.br/ojs/index.php/HOLOS/article/view/2096>. Acesso em: 21 jul. 2018.

MORYAMA, N.; PASSOS, M. M.; ARRUDA, S. M. Aprendizagem da docência do PIBID-Biologia. Alexandria: Rev. Educ. Cien. Tec., Florianópolis, v. 6, n. 3, p. 191-210, nov. 2013. Disponível em: <https://periodicos.ufsc.br/index.php/alexandria/article/view/38157/29099>. Acesso em: 20 ago. 2018.

NOFFS, N. A.; RODRIGUES, R. C. C. A Formação Docente: PIBID e o Estágio Curricular Supervisionado. Revista e-Curriculum, São Paulo, v. 14, n. 1, p. 357-374, jan./mar. 2016. Disponível em: <https://revistas.pucsp.br/index.php/curriculum/article/viewFile/26851/19384>. Acesso em: 20 ago. 2018.

OLIVEIRA, D. A. Regulação Educativa na América Latina: repercussões sobre a identidade dos trabalhadores docentes. Educação em Revista, Belo Horizonte, v. 44, p. 209-227, dez. 2006. Disponível em: <http:/ /www.scielo.br/pdf/edur/n44/a11n44.pdf> Acesso em: 17 maio 2018.

OREALC/UNESCO. La profesión docente y el desarrollo de la educación em América Latina y el Caribe. In: Boletin del Proyecto Principal de Educación em América Latina y el Caribe. Santiago, Chile: UNESCO, 1996.

PIOVEZAM, P. R.; DAL RI, N. M. A precarização do trabalho docente no estado de São Paulo: 20 anos de reformas. Educ. Temat. Digit. Campinas, v. 18, n. 1, p. 178-197, jan./abr. 2016.

RODRÍGUEZ, M. V.; VARGAS, M. B. A formação dos professores na América Latina: um balanço dos debates nos fóruns internacionais 1966-2002. In: RODRÍGUEZ, M. V.; ALMEIDA, M. L. P. Políticas Educacionais e formação de professores em tempos de globalização. Brasília: Liber Livro Editora, 2008. p. 37-56.

RODRIGUES, M. F.; KUENZER, A. Z. As Diretrizes Curriculares para o Curso de Pedagogia: uma expressão da epistemologia da prática. Olhar de Professor, Ponta Grossa, v. 10, n. 1, p. 35-62, 2007. Disponível em: <http://www.revistas2.uepg.br/index.php/olhardeprofessor/article/viewFile/1474/1119>. Acesso em: 20 jun. 2018.

SOUZA, A. R. B.; MARTINS FILHO, L. J. PIBID e docência: práticas e cenários. Diálogo, Canoas, n. 33, p. 39-56, dez. 2016. Disponível em: <https://revistas.unilasalle.edu.br/index.php/Dialogo/article/view/2238-9024.16.42/pdf>. Acesso em: 20 ago. 2018.

SOUZA, R. M. Q. O Programa institucional de bolsas de iniciação à docência numa universidade da grande São Paulo: depoimentos, contradições e reflexões preliminares. Acta Scientiarum. Education, Maringá, v. 36, n. 2, p. 309-316, jul./dez. 2014. Disponível em: <http://www.redalyc.org/pdf/3033/303331286014.pdf> Acesso em: 15 jul. 2018.

UNIVERSIDADE ESTADUAL DO MATO GROSSO DO SUL (UEMS). Coordenador Institucional. Implementação do PIBID no Mato Grosso do Sul. [23 de maio, 2016]. Campo Grande: Entrevista para pesquisa. Entrevista concedida ao Caroline Correia Maciel (MACIEL, Caroline Correia) - Entrevista realizada na pesquisa do relatório de dissertação.

UNIVERSIDADE FEDERAL DO MATO GROSSO DO SUL (UFMS). Coordenador Institucional. Implementação do PIBID no Mato Grosso do Sul. [16 de maio, 2016]. Campo Grande: Entrevista para pesquisa. Caroline Correia Maciel (MACIEL, Caroline Correia) - Entrevista realizada na pesquisa do relatório de dissertação.

RECEBIDO: 30/09/2018

APROVADO: 22/01/2019
RECEIVED: 09/30/2018

APPROVED: 01/22/2019
RECIBIDO: $30 / 09 / 2018$

APROBADO: 22/01/2019 